\title{
Quem dita as regras? A questão do pequeno poder das mulheres
}

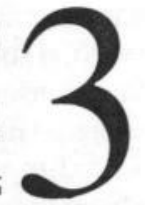

Tereza Cristina Pereira Carvalho Fagundes*

\section{RESUMO}

Trata-se de um artigo no qual se discute as relações de poder historicamente construídas, numa perspectiva de gênero. Configura a Educação como espaço, extensão do lar, onde a mulher tem vivenciado o seu (pequeno) poder, mas, principalmente, como a única possibilidade de mudança social e política capaz de assegurar-lhe um questionamento de sua própria condição feminina e de exercício pleno da cidadania.

\section{INTRODUÇÃO}

Gosto que me enrosco de ouvir dizer que a parte mais fraca é a mulher. Mas o homem com toda fortaleza desce da nobreza e faz o que ela quer.

Noel Rosa

* Doutoranda em educação da UFBA. Professor Adjunto IV. Coordenadora do Programa de Educação Sexual do Instituto de Biologia da UFBA. Membro da Diretoria da SBRASH. 
Será que a sabedoria popular consegue traduzir o que de fato acontece na sociedade? Quando ouvimos dizer que $o$ homem... faz o que ela (mulher) quer, trata-se, realmente, de uma verdade? E se verdade, o quanto tem de absoluta ou o quanto é relativa?

Poder significa domínio, força, autoridade, dominação.

Partimos do pressuposto de que o poder é relacional, ou seja, só existe no contexto das relações onde há um que domina porque há um outro que aceita o estado de ser dominado. Considerando que nas relações sociais entre homens e mulheres, um dos indivíduos envolvidos é o mais forte e o outro, o subordinado, questionamos: quando e em que circunstâncias a mulher consegue exercitar o poder, mostrar ou provar que tem algum poder sobre a situação, sobre o outro, sobre o homem?

Em verdade, já afirmou Foucault (1987), não existe o poder enquanto objeto natural, mas relações de poder como práticas socialmente construídas. Neste sentido procuraremos refletir como se construíram as relações de poder entre homens e mulheres, ou quem tem ditado as regras ao longo da história, no campo da educação e, mais especificamente, no exercício do magistério.

\section{1 - RELAÇÕES DE PODER NA HISTÓRIA}

Viver em sociedade é característica da espécie humana. Devido às suas carências e necessidades, os seres humanos foram compelidos a viverem juntos, vez que sua manutenção e sobrevivência dependiam da convivência e das relações sociais.

Registros históricos nos sugerem que houve um tempo em que a ordem social foi fluida e permissiva: as mães e outras mulheres da família cuidavam das crianças e a vida foi nômade e sedentária, a depender da escassez de alimentos e outras condições, o que provocava migração para diferentes regiões. Parece, também, ter havido rodízio de poder entre os indivíduos de um grupo e dos grupos entre si. Neste contexto, houve uma divisão social de trabalho a princípio arbitrária, mas o fato das mulheres ficarem grávidas alimentarem e protegerem os filhos lhes conduziu a alimentar e cuidar de todo o grupo, enquanto os homens exerciam atividades para a provisão de alimentos, como a caça e a pesca, para todo o grupo e principalmente para si (Engels, 1982).

Badinter (1986), analisando relações entre os sexos, retoma algumas lendas que narram a existência de tribos só de homens e só de mulheres, autônomas, cujos membros só se encontravam fortuitamente para se entregarem a folguedos amorosos. As crianças originadas desses encontros, de ambos os sexos, ficavam, no início, só com as mães e mais tarde, os meninos passavam para a tribo masculina. Para ela, circunstâncias adversas devem ter acontecido nas tribos femininas que as levaram a se unir à dos homens, ficando, em conseqüência, sob sua guarda. 
Outras lendas apontam para o mito da separação inicial - a mulher num espaço circunscrito, dedicando-se à colheita e ao cuidado dos filhos e os homens, num espaço mais vasto, dedicando-se à caça, assegurando o provimento de todos.

O fato de que a manutenção individual fosse a tarefa do homem e a sobrevivência da espécie fosse a tarefa da mulher era tido como óbvio; e ambas estas funções naturais, o labor do homem no suprimento de alimentos e o labor da mulher no parto, eram sujeitas à mesma premência de vida. (Arendt, 1995, p. 40)

Essas reflexões conduzem à suposição de haver existido em todas as sociedades e em todas as épocas, uma divisão sexual de trabalho com distinção valorativa das funções desempenhadas por homens e mulheres, fruto das relações entre eles, das relações sociais entre os gêneros. No âmago dessas relações, o masculino aparece como superior, independente, de grande significado e o feminino como inferior, dependente, de pouco significado; à mulher cabendo o lugar de subalterna, de quem historicamente não se construiu como sujeito, de quem pouco exerceu o poder, podendo apenas acumulá-lo e reproduzi-lo.

Tais colocações remetem-nos ao Patriarcado que se refere ao estado social no qual o pai, chefe da família, exerce sobre ela, a família, os direitos mais absolutos. Patriarcado diz respeito ao poder universal do homem sobre a mulher e sobre seus filhos. Universal no que tange à dominação do homem sobre o núcleo familiar e universal porque aparece em diversas culturas e épocas.

Buscando explicar esse estado de submissão das mulheres, nada natural, Pateman (1993) analisa a diferença entre liberdade e sujeição como uma diferença política, que tem raízes no "contrato social" ou pacto original. Para ela, esse contrato

é sexual no sentido patriarcal - isto é, o contrato cria o direito político dos homens sobre as mulheres - e também sexual, no sentido do estabelecimento de um acesso sistemático dos homens aos corpos das mulheres (...) ele é o meio pelo qual se constitui o patriarcado moderno. (ibid, p. 17)

Segundo esta autora, o Patriarcado Moderno se dá em termos de fraternidade ${ }^{1}$, de contrato e estrutura a sociedade civil capitalista. Enquanto o patriarcado tradicional utiliza a família como metáfora da ordem política,

1. Por um artifício mágico muito interessante, fraternidade, um termo relacionado com o parentesco, passou a ser tomado somente como uma metáfora dos vínculos universais da humanidade, da comunidade, da solidariedade ou do companheirismo... fraternidade significa o que diz: a irmandade de homens (Pateman, 1993, p. 121). 
entendendo todas as relações de superioridade e subordinação como semelhantes à relação pai-filho (Pateman, 1993, p. 127), o patriarcado fraternal moderno baseia-se na teoria do contrato social. O Patriarcado Moderno crê na abrangência maior do poder político instituído sobre bases diferentes e atribuído a fins diferentes do poder paterno; incorpora a noção de exploração por partẹ de quem exerce o poder, ou seja, o domínio do outro se dá através da sua exploração.

Também no final do século passado, os escritos de Marx e Engels (1970) vieram a se constituir em subsídios para se admitir que a identidade feminina e os papéis desempenhados pelas mulheres têm suas raízes na relação entre estrutura econômica e sociedade. Para eles, em razão do incremento da produtividade, do aumento das necessidades e do crescimento populacional, ocorreu, então, a formação da consciência gregária ou tribal e em decorrência, a divisão do trabalho, divisão essa estabelecida em função das diferenças de gêneros e idades no interior dos grupos sociais. A primeira divisão do trabalho se fez entre o homem e a mulher na criação dos filhos. Posteriormente, com o aperfeiçoamento das forças produtivas e o surgimento de excedentes de produção, a divisão do trabalho tornou-se mais complexa: uma parte da população passou a administrar o processo produtivo, do qual progressivamente se apoderou do produto (e deteve o poder), e a outra parte ficou com o papel de reproduzir (e em conseqüência, ser submissa, uma vez que reproduzir, socialmente, vinha em segundo plano em relação ao produzir, prover). Diante disso, depreende-se que a propriedade privada foi decorrente da divisão e da alienação do trabalho. Uma releitura das posições de Marx e Engels permite concluir que os homens passaram à situação de donos do poder e as mulheres, de excluídas e submissas embora se considere não ser simétrica a relação entre dominantes e dominados.

Como a divisão do trabalho aparece sob variadas formas na sociedade, o modo de produção do homem e da mulher numa mesma classe social e qualquer que seja a classe, nem sempre é o mesmo. Sob esse prisma, Saffioti (1976) nos coloca dois pontos básicos para reflexão:

Primeiro que, passada a fase de acumulação originária do capital, as oportunidades de trabalho para as mulheres passaram a ser reguladas de modo diverso, deixando de refletir a dinâmica própria de cada fase de desenvolvimento da formação social-capitalista. $O$ segundo ponto (...) é que, com o desenvolvimento gigantesco da tecnologia, $e$, conseqüentemente, com a crescente elevação da produtividade do trabalho humano, a sociedade de classes dispensa, para a criação de sua riqueza, o concurso de todos os seus membros adultos normais. (Op. cit., p. 301)

Obviamente, neste contexto, a história tem revelado que quando o mundo do trabalho precisa reduzir seu quadro de trabalhadores, a dispensa 
do trabalho feminino é consideravelmente maior e mais freqüente, do que do trabalho masculino, dado este que reforça o direcionamento da personalidade feminina para valores mais ligados à vida familiar e o da personalidade masculina para a competição pelo mercado de trabalho e ajustes necessários aos diversos papéis que se espera, o homem deva desempenhar. Mas a mulher insistindo em penetrar e permanecer no mundo do trabalho, na vida pública rompe barreiras,

fá-lo, entretanto, sob o signo da inferioridade que o sexo feminino representa em relação ao masculino. É ocupando as posições inferiores, recebendo salários menos compensadores, não aspirando aos postos de mando que a mulher "resolve" ou alivia as tensões que a inconsistência de seus papéis origina. (Saffioti, 1976, pp. 307-308)

Dentre os postos ocupados, nessas circunstâncias está o de educadora, de professora ou outros, vinculados, primordialmente, a instituições de ensino e todas das áreas do cuidar e do servir, como veremos a seguir.

\section{2 - EDUCAÇÃO - UM ESPAÇO DE (PEQUENO) PODER DAS MULHERES}

Ao longo da história da humanidade, homens e mulheres receberam formas diferenciadas de educação, tanto por parte da família quanto de outras instituições sociais voltadas para a sua formação. Para os homens, desde crianças, tudo: o acesso ao mundo público, o saber, a aventura, o domínio e a conquista de novos horizontes; para as meninas, uma série de restrições com vistas à manutenção do que, à natureza era atribuído: temperamento dócil, subserviente, submisso, a fraqueza, a circunscrição ao espaço doméstico, etc.

Graças a uma polêmica iniciada na França, por Cristine de Pizan, conhecida como a Querelle des Femes que durou quatro séculos, a partir do século XV, o direito à educação tornou-se uma reivindicação primordial das mulheres. Também Poulain de la Barre ${ }^{2}$, um pensador do século XVII, defendeu a noção de igualdade de ambos os sexos e a necessidade das mulheres terem as mesmas possibilidades de estudo que os homens para desenvolverem as mesmas habilidades e poderem se sobressair nas mesmas carreiras. (Cobo, 1995).

2. Autor de obras polêmicas para a época: De l'égalité des deux sexes, De l'éducation des dames pour la conduite de l'ésprit dans les sciences et dans les moeurs e De léxcellence des hommes contre l'égalité des sexes. 
Havia, entretanto, fortes barreiras nesse sentido. Marcante pensador iluminista, Jean Jacques Rousseau ao escrever "O Emílio", em 1762 tratou da educação da mulher (Sophie), tendo como parâmetro àquela destinada ao homem (Émile). Para ele, a educação feminina devia ser feita em analogia à masculina, cabendo à mulher agradar o homem, ser-lhe útil, fazer-se amada e estimada; educar o homem quando jovem, cuidá-lo quando adulto, consolá-lo, fazer-lhe a vida agradável e doce. E, ainda mais, Rousseau defendia que deveres femininos de todas as épocas deviam ser ensinados às meninas desde a mais tenra idade (Rousseau, 1973). O Emílio, como tratado sobre a educação, apresenta a concepção de família, de mulher e de âmbito privado, numa rígida direção patriarcal.

Confrontando princípios como os de Rousseau e estendendo os ideais da Revolução Francesa, Mary Wollstonecraft (1996) em sua obra Vindication of the Rights of Woman, escrita no final do século XVIII em Londres, contrapôs-se às grandes correntes de pensamento, que se constituíam também, correntes de tensão social, de sua época e de seu país. Argumentava, inclusive, que a força corporal era a única base sólida (e devida à natureza) sobre a qual se fundamentava a superioridade masculina; todos os demais argumentos que colocaram, historicamente, as mulheres numa posição "inferior" aos homens tinham raízes culturais, socialmente construídas, ao contrário de serem devidas à "natureza" ou à chamada "essência feminina". Nesse sentido, os direitos das mulheres por ela reivindicados, foram: ter acesso ao conhecimento, e, por conseqüente, à educação; não ser subjugadas aos homens e poder exercitar o poder e ter acesso ao mundo público.

A obra de Wollstonecraft foi um texto revolucionário que de Londres, logo alcançou toda a Europa e Estados Unidos ${ }^{3}$. No Brasil, a partir da assimilação das concepções de Wollstonecraft, Nísia Floresta criou um novo texto, reivindicando direitos femininos adequados ao cenário nacional. (Floresta, 1989a). Precursora do feminismo denunciou a superioridade masculina apoiada na força física dos homens, nas diferenças anatômicas existentes entre os corpos dos homens e das mulheres e defendeu, veementemente, o direito das mulheres de terem acesso à mesma educação que tinham os homens.

Enquanto isso, o processo educacional para homens e para mulheres que teve sua origem com os jesuítas da Companhia de Jesus, seguia os preceitos da Ratio Studiorum ${ }^{4}$, formando apenas uma elite letrada e culta, além

3. Logo após a edição inglesa essa obra foi traduzida em Paris. Em dez anos, foi reeditada, sete vezes, na França, Inglaterra, Estados Unidos e Escócia.

4. A Ratio Studiorum (1586-1599) constitui-se na metodologia humanista católica que orientou os jesuítas a educarem com base na preleção, contenda ou emulação, memorização, expressão e imitação, tornando-se um dos pilares da escola tradicional (Manacorda, 1996). 
de novos sacerdotes, visto que a sociedade brasileira calcada na agricultura e no trabalho escravo, não pretendia dar qualificação profissional a seus filhos (Giles, 1987). Nesse contexto, a Companhia de Jesus, no Brasil, fundou a primeira escola para meninas, ainda que restrita ao ensino das boas maneiras e prendas domésticas além da catequese. Por isso, a educação da mulher mantinha-se atrelada às concepções do ser feminina, reforçadas desde a mais remota antigüidade: mulher é aquela que cuida da casa e da preparação dos alimentos, reproduz - dá origem e cuida dos filhos, cozinha, tece, é fraca, inferior ao homem, por isso subjugada, oprimida, etc.

Com a vinda da Corte portuguesa para o Brasil surgiram oportunidades de instrução laica para a mulher, ainda que dentro do modelo vigente $\mathrm{e}$ em número insuficiente para atender a toda população. A Constituição Brasileira de 1823 desencadeou a formalização da educação para o sexo feminino e foram criadas as escolas de primeiras letras em todas as cidades, vilas e lugarejos mais populosos do Império. Para fazê-las funcionar foram também nomeadas mestras de meninas que, no julgamento do presidente de cada província, se mostrassem dignas de tal ensino bem como das artes de coser e de bordar. $\mathrm{O}$ ensino da aritmética foi restrito às quatro operações e houve exclusão da geometria, configurando-se o mínimo em matéria de instrução. As mulheres que ensinavam as meninas eram também menos capazes e, acrescente-se, menos bem pagas do que os homens que instruíam os meninos (Hanner, 1981).

A inadequação dessas escolas estimulou a criação de escolas especializadas na formação de professores - as Escolas Normais. A primeira foi em Niterói, em 1835, segunda na $B a h i a^{5}$, em 1836 e a terceira em São Paulo, dez anos depois. Assim, na Segunda metade do século XIX, cresceram as oportunidades educacionais para as mulheres com o aumento de escolas para meninas e a criação das escolas normais, embora muitas jovens ainda continuassem a receber por muitos anos uma instrução sumária em casa ou em escolas particulares, algumas das quais orientadas por religiosos e outras dirigidas por estrangeiras (Hahner, 1981, p. 31).

Com a criação das Escolas Normais, houve a inserção da mulher como profissional de educação. A pretensão inicial dessas escolas foi dar formação profissional adequada a homens e mulheres, para resolver o problema do abandono da educação nas escolas provinciais que vinha ocorrendo e sendo denunciado desde o Império. Pouco a pouco, entretanto, essas escolas foram recebendo e formando mais mulheres do que homens. Por um lado esta tendência foi atribuída à concepção do magistério como extensão da maternidade, destino "primordial" das mulheres, mas por outro, à série de intervenções de controle do Estado sobre a docência, ao determinar conteúdos e níveis de ensino, exigir credenciais dos educadores e horários

5. Escola Normal da Bahia, hoje Instituto Central de Educação Isaías Alves (ICEIA). 
livres para o ensino, que por certo, associadas a condições como baixo salário dos docentes, afastaram os homens dessa carreira e os conduziram a profissões mais rentáveis. O magistério foi, dessa forma, tornando-se uma ocupação essencialmente feminina. ${ }^{6}$

Ao constatarem a alta incidência de mulheres no magistério, Bruschini e Amado (1988) concluíram que, neste século, o Magistério tornou-se um dos guetos ocupacionais das mulheres, para umas, por vocação e para outras, como estratégia de ascensão. Corroboram estes dados o estudo de Novaes (1984) que, buscando compreender os motivos que levam as mulheres à escolha do magistério, encontrou como resposta mais freqüente, a vocação, traduzida por gostar de lidar com crianças, ter jeito para dar aula e gostar de ajudar ao próximo, dados considerados pela autora muito ligados ao preconceito, ainda presente em nossa sociedade, de que o magistério é profissão feminina.

Ao conceito de vocação, historicamente construído, subjaz a idéia de que as pessoas têm um conjunto de tendências, aptidões e habilidades inatas para certos trabalhos, atividades e ocupações. Constitui-se, dessa forma, num mecanismo eficiente, incorporado pelas mulheres (e também pelos homens) que emerge no processo de suas escolhas profissionais. No caso das mulheres, em particular, a sua "destinação" para carreiras como o magistério, soma-se ao que a sociedade vem definindo como características e necessidades femininas: ser paciente, ter jeito para lidar com crianças, ser abnegada, altruísta, e, até mesmo, poder conciliar as atividades profissionais às domésticas, continuamente assumidas.

Com o desenvolvimento econômico da década de 50 e a expansão dos sistemas de ensino, aumentaram-lhes as oportunidades. Cresceu o nível de escolaridade feminina, mas o magistério continuou sendo o curso mais procurado. Entretanto, isto não significava que todas as normalistas ${ }^{7}$ fossem exercer a profissão de professora após a formatura. Muitas estudavam apenas para assegurar a cultura geral propiciada pela Escola Normal bem como o prestígio que o diploma de professora lhes conferia ${ }^{8}$. Ser professora quer a nível secundário, quer a nível superior, assegurava um status de prestígio social à "futura" esposa e mãe e permitia-lhe uma espécie de equiparação à formação cultural e acadêmica do "futuro" marido.

Quanto ao acesso das mulheres à educação superior, no início desse século, poucas "ousavam" se dirigir a áreas como a Medicina, Direito e Engenharia, tidas como masculinas e por isso, mais privilegiadas. Somente com a criação das Faculdades de Filosofia, congregando os cursos de Filosofia, Letras, Pedagogia, dentre outros, a situação foi se modificando. Nesta

6. Para mais detalhes, ver Safiotti (1976) e Demartine e Antunes (1993).

7. Normalista era o nome dado às alunas que faziam o curso de formação de professoras para o ensino elementar, na época nomeado Curso Normal.

8. Ver o estudo de Bassanezi (1997). 
época, em 1932, surgiu também a primeira "escola de educação" de nível universitário no Brasil - a Escola de Professores.

Nas décadas seguintes houve um crescimento absoluto do número de alunas no ensino superior, bem como, a concentração das mesmas em carreiras que conduziam ao magistério secundário definidas culturalmente, como mais apropriadas à condição feminina - Letras, Ciências Humanas e Filosofia - que inclui a categoria Curso de Pedagogia' ${ }^{9}$. Esses cursos, entretanto, não eram vistos especificamente como uma profissão e sim como uma formação. Por isso, analisa Passos (1997b)

a ida das mulheres para um curso que não visasse ganhar dinheiro trazia subjacente a indicação de que elas continuariam sendo mantidas pelo homem, o que eqüivale a ser dominada, tutelada, oprimida. (ibid., p. 115)

Também a preferência feminina por cursos de formação de educadores, como os de Faculdades de Filosofia é analisada por Passos (1997a) como decorrente da percepção desses cursos, pela sociedade, como mais afeitos às mulheres do que aos homens, por não lhes ameaçarem as funções de mãe e de esposa, e, pelo contrário, até contribuírem para a sua exaltação e maior eficiência. A cultura da época viu as Faculdades de Filosofia exigindo

um "saber desinteressado", certamente em oposição àquelas que visavam dar aos indivíduos um "saber interessado", o que se pode traduzir por: prático, produtivo e economicamente valioso. Do mesmo modo poderia ler-se, enquanto aqueles se caracterizavam pela profissionalização, esses deviam ser realizados por dedicação, diletantismo ou filantropia. (ibid., p. 116)

Essa conclusão referenda o estudo sobre o acesso da mulher ao ensino superior brasileiro realizado por Barroso e Mello (1975). Afirmam as pesquisadoras que, após vencerem as barreiras de natureza econômica e os obstáculos de natureza psico-social que, muitas vezes, as impedem de cursarem uma faculdade, as mulheres se direcionam a carreiras, que a sociedade delimita como mais adequadas a elas.

E assim, constatamos que, mesmo podendo ter sonhos diversificados, a ideologia presente em nossa sociedade conduz as mulheres aos papéis de mãe e de esposa, aos quais devem dar sempre o melhor de si, mantendo-as dependentes, submissas, conformadas, desempenhando carreiras limitadoras, de prestígio insignificante e mal remuneradas, ainda que seja elevado o nível escolar exigido. O magistério solidificou-se

9. Ver o estudo de Barroso e Mello (1975). 
como profissão feminina posto que, cuidar e servir, adequavam-se perfeitamente à destinação da mulher.

A opção por cursos de formação de educadores bem como o exercício do magistério, prevalentemente por mulheres tem conduzido ao esterétipo de menosprezo social para com a educação por ser campo feminino e, por conseguinte, de associar este campo à crença de ser ele descrito como um dos mais insatisfatórios: baixos salários, condições inadequadas de trabalho, preconceito em relação à capacidade intelectual dos que a ele se destinam, pouco prestígio social, etc.

Por outro lado, nos dias atuais há mulheres exercendo trabalho remunerado em áreas tidas como masculinas, sendo engenheiras juízas, dentre outras, assim como ocupando cargos de chefia e direção. Algumas mulheres encontram no ambiente de trabalho, verdadeira réplica do sistema patriarcal; outras só trabalham em instâncias "próximas" à familiar como creches, escolas, associações de bairros, secretarias de educação e de bem estar social, atividades estas que se inserem no mundo da reprodução, historicamente a elas reservado. Há muitas mulheres que se sobrecarregam de tarefas ditas "femininas" e se vêm às voltas com a chamada tripla jornada, sobrepondo às atividades profissionais àquelas tradicionalmente inerentes à esfera privada - "cuidar dos filhos, do marido, da casa". No campo da política há mulheres (embora em número reduzido) exercendo cargos, de vereadoras a senadoras e até ministras de Estado, mas que por vezes precisam se submeter aos interesses conservadores de quem lhes subsidiam financeiramente, para assegurar suas próximas campanhas, seus próximos mandatos... (Costa, 1997). No caso das vereadoras, constata-se que as lutas por elas empreendidas circunscrevem interesses, que são extensão do doméstico: creches, escolas, abrigo de velhos, etc. Quanto ao seu processo de educação.

... apesar das conquistas que as mulheres tiveram a partir dos anos 70, inclusive no concernente ao livre acesso a qualquer curso universitário, elas incorporaram de tal forma a ideologia dominante que as destina a certas carreiras, que continuam, no geral, encaminhando-se para elas. (Passos, 1997b, p. 160)

Para a pesquisadora a situação de escolha profissional ultrapassa as relações de gênero e penetra as relações de classe, uma vez que os cursos de formação de professores são considerados menos exigentes, menos dispendiosos e podem ser cumpridos em menos tempo do que outros de outras áreas. Essas condições asseguram a essas mulheres, levadas por uma necessidade de ascensão profissional e financeira, a possibilidade de mais rapidamente se engajarem num trabalho em relação a outras que se dirigem a carreiras que requerem mais tempo para terminalização bem como, uma maior concorrência de homens na entrada para o mercado de trabalho. 


\section{CONCLUSÃO (OU NÃO?)}

A análise sobre as relações de poder historicamente construídas, embora breve, nos permite admitir que se as mulheres não podem ter o poder, detém em certos grupamentos como o lar e a educação, pequenos poderes ou fragmentos múltiplos equivalentes a influências difusas e periféricas. (Perrot, 1988, p. 167)

No início do século, havia o discurso da dominação masculina recorrente de chamamento das mulheres para o lar e agora, no final, há uma dominação mascarada pelo discurso de igualdade de oportunidades face à educação e o trabalho. Na realidade, há um pequeno número de mulheres visíveis no poder, enquanto a grande maioria não chegou ao desejado e socialmente justo; as mulheres ainda lutam pela possibilidade de "se igualar" aos homens, mas por vezes vivem sob o seu jugo, em espaços e lugares, freqüentemente, por eles delineados.

Nesta conjuntura, em nosso entender, a educação da mulher configura-se como a única possibilidade de mudança social e política, capaz de assegurar um questionamento de sua própria condição feminina, uma redefinição de seu papel como cidadã ao nível público, mesmo sabendo que ao ditar as regras, ao romper com a sua condição de invisibilidade, provocará tensões, pois que, pais maridos e filhos a verão como agentes de subversão do cotidiano familiar e dos padrões acordados no interior da família e da sociedade.

\section{REFERÊNCIAS BIBLIOGRÁFICAS}

ARENDT, H. A condição humana. Rio de Janeiro: Forense Universitária, 1995.

BADINTER, E. Um é o outro. Relações entre homens e mulheres. Rio de Janeiro: Nova Fronteira, 1986.

BARROSO, C. L. M. e MLLO, G. N. O acesso da mulher ao ensino superior brasileiro. In: Cadernos de Pesquisa. № 15, dez. 75. p. 47-77.

BRUSCHINI, M. C. e AMADO, T. Estudos sobre a mulher e educação: algumas questões sobre o magistério. Cadernos de Pesquisa. São Paulo: Fundação Carlos Chagas (64): 4-13, fev. 1988.

COBO, R. Fundamentos del patriarcado moderno. Jean Jacques Rousseau. Madri: Cátedra, 1995.

COSTA, A. A. As donas do poder. Mulher e política na Bahia. Salvador: NEIM/ ALBa, 1998.

DEMARTINI, Z. F. e ANTUNES, F. F. Magistério primário, profissão feminina, carreira masculina. Cadernos de Pesquisa. № 86, ago. 93. p. 5-14.

ENGELS, F. A origem da família, da propriedade privada e do Estado. $8^{\mathrm{a}} \mathrm{ed}$. Rio de Janeiro: Civilização Brasileira, 1982. 215 p.

FOUCAULT, M. Vigiar e punir: nascimento da prisão. Trad. Lígia M. Pondé Vassalo. Petrópolis: Vozes, 1987. 
FLORESTA, N. Direito das mulheres e injustiça dos homens. $4^{\mathrm{a}}$ ed. Atualizada com introdução, notas e posfácio da Constância Lima Duarte. São Paulo: Cortez, 1989.

GILES, T. R. História da educação. São Paulo: EPU, 1987.

HANNER, J. A mulher brasileira e suas lutas sociais e politicas: 1850-1937. São Paulo: Brasiliense, 1981.

MANACORDA, M. A. História da educação - Da antigüidade aos nossos dias. São Paulo: Cortez, 1996.

MARX, K. e ENGELS, F. A ideologia alemã. Teses para Feuerbach. São Paulo: Moraes, 1984.

PASSOS, E. S. A faculdade de filosofia e a construção da identidade de gênero. In: ALVARES, M. L. M. e SANTOS, E. F. (orgs.) Desafios de identidade. Espaço-Tempo de mulher. Belém: CEJUP, 1997. p. 113-122a.

PASSOS, E. S. A mulher na UFBA. In: PASSOS, E. S. (org.) Um mundo dividido O gênero nas universidades do norte e nordeste. Salvador: UFBA, 1997. p. $113-162 b$.

PATEMAN, C. $O$ contrato sexual. Rio de Janeiro: Paz e Terra, 1983.

PERROT, M. Os excluídos da história. Rio de Janeiro: Paz e Terra, 1988.

ROUSSEAU, J. J. O Emílio ou da educação. Trad. Sérgio Millet. $2^{2}$ ed. São Paulo: Difel, 1973.

SAFFIOTI, H. I. B. A mulher na sociedade de classes: mito e realidade. Petrópolis: Vozes, 1976,

WOLLSTONECRAFT, M. Vindicación de los derechos de la mujer. Madrid: Cátedra, 1996. 